\title{
Predictors of Enrolment in the National Health Insurance Scheme Among Women of Reproductive Age in Nigeria
}

\author{
Bolaji Samson Aregbeshola $^{{ }^{*}}$, Samina Mohsin Khan ${ }^{2}$
}

\begin{abstract}
Background: Despite the implementation of the National Health Insurance Scheme (NHIS) since 2005 in Nigeria, the level of health insurance coverage remains low. The study aims to examine the predictors of enrolment in the NHIS among women of reproductive age in Nigeria.

Methods: Secondary data from the 2013 Nigeria Demographic and Health Survey (NDHS) were utilized to examine factors influencing enrolment in the NHIS among women of reproductive age $(n=38948)$ in Nigeria. Demographic and socio-economic characteristics of women were determined using univariate, bivariate and multivariate analyses. Data analysis was performed using STATA version 12 software.

Results: We found that $97.9 \%$ of women were not covered by health insurance. Multivariate analysis indicated that factors such as age, education, geo-political zone, socio-economic status (SES), and employment status were significant predictors of enrolment in the NHIS among women of reproductive age.

Conclusion: This study concludes that health insurance coverage among women of reproductive age in Nigeria is very low. Additionally, demographic and socio-economic factors were associated with enrolment in the NHIS among women. Therefore, policy-makers need to establish a tax-based health financing mechanism targeted at women who are young, uneducated, from poorest households, unemployed and working in the informal sector of the economy. Extending health insurance coverage to women from poor households and those who work in the informal sector through a tax-financed non-contributory health insurance scheme would accelerate progress towards universal health coverage (UHC).

Keywords: National Health Insurance, Enrolment, Women, Universal Health Coverage, Nigeria

Copyright: (c) 2018 The Author(s); Published by Kerman University of Medical Sciences. This is an open-access article distributed under the terms of the Creative Commons Attribution License (http://creativecommons.org/ licenses/by/4.0), which permits unrestricted use, distribution, and reproduction in any medium, provided the original work is properly cited.

Citation: Aregbeshola BS, Khan SM. Predictors of enrolment in the National Health Insurance Scheme among women of reproductive age in Nigeria. Int J Health Policy Manag. 2018;7(11):1015-1023. doi:10.15171/ijhpm.2018.68
\end{abstract}

Article History:

Received: 7 March 2018

Accepted: 21 July 2018

ePublished: 6 August 2018

\section{Key Messages}

Implications for policy makers

- The National Health Insurance Scheme (NHIS) has not provided access to healthcare services and financial risk protection for a large proportion of women and poor households in Nigeria.

- Voluntary contributory health insurance scheme for women from poor households and those working in the informal sector may not be feasible in expanding health insurance coverage due to financial constraint and difficulty in collecting contributions among these groups.

- Addressing the problem of poor uptake of health insurance among women from poor households require a special protection and tax-based health financing mechanism.

Implications for the public

There are concerns about the effectiveness of the National Health Insurance Scheme (NHIS) to expand health insurance coverage to women from poor households and those working in the informal sector. The law establishing the NHIS need to be re-examined while the expansion of health insurance coverage for women of reproductive age who remain uninsured must be considered. Governments and policy-makers need to engage women of reproductive age in discussing feasible pathways for achieving universal health coverage (UHC) as a goal of the Sustainable Development Goals (SDGs) by 2030. Despite the goal of the NHIS to ensure that all population groups regardless of their socio-economic status (SES) have access to quality and affordable healthcare services, majority of women of reproductive age are not enrolled in the scheme. However, there is a need for women of reproductive age to demand health financing reform and political leadership from governments and policy-makers.

\section{Background}

Expanding health insurance coverage to people in the informal sector of the economy is a major challenge in most low- and middle-income countries (LMICs). This is due to large informal sector populations in these countries. According to International Labour Office (ILO), over $60 \%$ of the world's employed population are in the informal sector of the economy. ${ }^{1}$ Developing countries have about $90 \%$ of 
informal employment as a percentage of total employment. ${ }^{1}$ However, Africa has about $86 \%$ of informal employment as a percentage of total employment. ${ }^{1}$ Nigeria has over $90 \%$ of informal employment as a percentage of total employment. ${ }^{1}$ The informal sector comprises mostly of the poor and vulnerable groups who are unable to pay for healthcare or work in enterprises where it is difficult to collect insurance contributions. ${ }^{2,3}$

Health insurance has been shown to be an important health financing mechanism in improving access to healthcare services and providing financial risk protection. ${ }^{4-12}$ Furthermore, there is a global call for countries to move towards universal health coverage (UHC) through sustainable health financing. ${ }^{13} \mathrm{UHC}$ has become an important target of the Sustainable Development Goals (SDGs). ${ }^{14} \mathrm{UHC}$ aims to increase equity in access to quality healthcare services and reduce associated financial risk. ${ }^{15}$

According to the World Bank and World Health Organization (WHO), at least half of the world's population still lacks access to essential health services. ${ }^{16}$ The 2018 World Health Statistics also revealed that the UHC service coverage index for Nigeria is $39 \% .{ }^{17}$ Pre-payment mechanism has been advocated as the best option to ensure access to care based on need rather than ability to pay and protect households from associated financial risk. ${ }^{13}$ Despite the implementation of the National Health Insurance Scheme (NHIS) since 2005 in Nigeria, the level of health insurance coverage remains low. ${ }^{18-20}$ Therefore, there is a need to understand the factors responsible for the low level of enrolment in the NHIS.

Many studies have been conducted on the determinants of NHIS enrolment in Africa. ${ }^{3,21-42}$ Results from these previous studies revealed that factors such as age, education, place of residence, region of residence, marital status, ethnicity, employment status, household wealth, gender, household size and exposure to media were predictors of enrolment in the NHIS. However, there is limited evidence on the predictors of enrolment in the NHIS among women of reproductive age in Nigeria using a nationally representative household survey. Evidence suggests that gender plays an important role in NHIS enrolment. ${ }^{28}$ Women face different health risk and difficulties in accessing healthcare services. ${ }^{34}$ They also bear a greater burden of disease and have limited access to resources. ${ }^{29,34}$ The ILO revealed that a higher percentage of women are in informal employment than men. ${ }^{1}$ It is against this background that the study aims to examine factors associated with enrolment in the NHIS among women of reproductive age in Nigeria in order to inform policy decisionmaking towards addressing the problem of low enrolment in the NHIS. The study contributes to the literature in Africa and to better understanding of the correlates of enrolment in the NHIS among women of reproductive age in Nigeria.

Overview of the National Health Insurance Scheme in Nigeria

After many attempts at having legislation on health insurance since the 1960s, the NHIS, although established in 1999, became operational in 2005 to ensure access to quality healthcare services, provide financial risk protection, reduce rising cost of healthcare services and ensure efficiency in healthcare. ${ }^{43}$ The NHIS law made enrolment in the scheme optional. ${ }^{43}$ NHIS membership is mandatory for workers in the formal sector while it is voluntary for those in the informal sector. ${ }^{43}$ Formal sector workers, a spouse and their dependents under the age of 18 years are automatically enrolled into the NHIS based on a $5 \%$ monthly contribution from worker's basic salary and payment of $10 \%$ of worker's basic salary by the employer. ${ }^{43}$ Informal sector workers are expected to voluntarily enrol by making annual premium payments which varies depending on the health insurance plan. ${ }^{43}$ States are not legally mandated to provide health insurance to the people ${ }^{43}$ but there is a current drive to decentralise social health insurance (SHI) scheme to the states. NHIS has been implemented through programmes such as Formal Sector Social Health Insurance Programme (FSSHIP), Mobile Health, Voluntary Contributors Social Health Insurance Programme (VCSHIP), Tertiary Institution Social Health Insurance Programme (TISHIP), Community Based Social Health Insurance Programme (CBSHIP), Public Primary Pupils Social Health Insurance Programme (PPPSHIP) and the Vulnerable Group Social Health Insurance Programme (VGSHIP) which aims to provide healthcare services for children under 5 years, pregnant women, prison inmates, disabled persons, retirees and the elderly. ${ }^{43}$ The NHIS target different population groups including women and those in the informal sector with the aim of working toward UHC. ${ }^{44}$ Over a decade since its implementation, evidence suggests that the NHIS has provided health insurance coverage to less than $5 \%$ of the Nigerian population. ${ }^{18-20}$ This implies that the NHIS has failed to reach all population groups especially the poor, vulnerable and informal sector populations. Consequently, the poor, vulnerable and informal sector populations have to pay out-of-pocket (OOP) for healthcare services. OOP payments continue to be a major source of financing healthcare in Nigeria. ${ }^{45}$ In addition, OOP payments have been regarded as an inequitable source of financing healthcare ${ }^{46}$ with catastrophic and impoverishing effects on individuals and households. Globally, over 800 million people spend at least $10 \%$ of their household budget paying for healthcare while about 100 million fall into extreme poverty due to OOP health payments. ${ }^{16}$ A study on the catastrophic and impoverishing effects of OOP health payment in Nigeria revealed that about $17 \%$ of households incurred catastrophic health payments at $10 \%$ threshold of total consumption expenditure while about 1.3 million Nigerians were being pushed below the poverty line due to OOP health payments. ${ }^{47}$ However, enrolment in health insurance increases the likelihood of using general healthcare. ${ }^{5,48-50}$ SHI programme has entrenched inequities in access to healthcare as only federal government workers and their dependents are provided with health insurance coverage.$^{18}$ Furthermore, the better-offs are more likely to enrol in the NHIS than poor households. This could be due to poor household's low earning capacity, inability to pay premium contributions and poor awareness. Community-based health insurance ( $\mathrm{CBHI}$ ) scheme has failed to expand coverage to the poor, vulnerable and informal sector populations. ${ }^{51}$ Private voluntary health insurance (VHI) has shown poor potential 
to extend health insurance coverage. ${ }^{52}$ Exemption schemes and waivers targeted at the poor and vulnerable groups have not been effective in increasing enrolment and addressing the barriers to accessing healthcare for these groups due to problems associated with targeting. The poor, vulnerable and informal sector populations are disproportionately exposed to catastrophic and impoverishing effects of high OOP payments. NHIS as an agency of government operate under the Federal Ministry of Health (FMoH). ${ }^{43}$ This agency registers and accredits health maintenance organizations (HMOs) and healthcare providers (HCPs). HMOs collect contributions and pay monthly capitation or fee-for-service (FFS) to HCPs for services provided. HCPs are registered private and public hospitals and clinics at the primary, secondary and tertiary levels that provide healthcare services to NHIS enrolees who are registered through an HMO. ${ }^{43}$ Despite the disentanglement of the NHIS (as an implementing and regulatory agency), HMOs and HCPs; the NHIS has been bedevilled with poor governance, mismanagement of fund, corruption as well as lack of transparency and accountability. NHIS fund is obtained from general government revenues; premium contributions; returns from investments as well as grants or donations. The NHIS covers over $95 \%$ of disease conditions that affect the Nigerian population. The benefit package under the FSSHIP which serve most of the NHIS enrolees includes out-patient services, in-patient services, maternity care for up to four live births, emergencies, preventive care including immunisation, consultation with specialists, eye examination and care, preventive dental care and pain relief as well as a range of prostheses. ${ }^{43}$ Some of the benefits the NHIS has brought since its inception is access to healthcare for formal sector workers and their dependents as well as tertiary level students who pay a premium of N2000 (US\$5) per annum. The NHIS has also reduced OOP health payments for this group of enrolees.

\section{Methods}

Data Source

Secondary data from the 2013 Nigeria Demographic and Health Survey (NDHS) were used for the study. NDHS is a nationally representative cross-sectional study conducted by the National Population Commission (NPC) with funding by United States Agency for International Development (USAID), the United Kingdom Department for International Development (DFID) through Partnership for Transforming Health Systems Phase II (PATHS2), and the United Nations Population Fund (UNFPA) with technical support from ICF International. ${ }^{53}$ The NDHS 2013 provides updated estimates of the basic demographic and health indicators covered in the earlier surveys such as fertility levels, marriage, fertility preferences, awareness and use of family planning methods, child feeding practices, nutritional status of women and children, adult and childhood mortality, awareness and attitudes regarding HIV/AIDS, in addition, to information on violence against women. ${ }^{53}$

\section{Study Design}

This was a retrospective cross-sectional study comprised of
38948 women aged 15-49 years.

\section{Data collection}

Relevant data for the study were extracted from the 2013 NDHS dataset. Among the numerous variables in the women's recode, only eleven variables were selected for the purpose of this study. The data were thereafter cleaned, re-categorized and recoded as necessary.

\section{Variables Measurement \\ Dependent Variable}

The dependent and/or outcome variable is health insurance coverage coded as 1 if covered by health insurance and 0 otherwise.

\section{Independent Variables}

The independent and/or explanatory variables were guided by Andersen's Behavioural Model, ${ }^{54}$ Grossman's Model of Demand for Health ${ }^{55}$ and literature review on the determinants of enrolment in NHIS. ${ }^{3,21-42}$ In Andersen's Behavioural Model, the variables that determine women's decision to enrol in the NHIS are categorized into three namely: predisposing factors (age, gender, ethnicity and household head characteristics); enabling factors (location, geo-political zone, education, health insurance status and household income); and need factors (perceived severity of illness, self-reported health status, presence of physician diagnosing chronic diseases and overweight). These factors interact with each other to determine whether or not women enrol in the NHIS. According to Grossman, the demand for health is influenced by factors such as age, wage rate and education. ${ }^{55}$ Grossman's model of demand for health proposes that health can be viewed as a durable capital stock that produces an output of healthy time. ${ }^{55}$ A person determines his optimal stock of health capital at any age by equating the marginal efficiency of this capital to its user cost in terms of the price of gross investment. ${ }^{55}$ The model explains variations in both health medical care among persons in terms of variation in supply and demand curves for health capital. ${ }^{55}$ Grossman's model predicts that if the rate of depreciation increase with age, at least after some point in the life cycle, then the quantity of health capital demanded would decline over the life cycle. ${ }^{55}$ Another prediction is that a consumer's demand for health and medical care should be positively correlated with his wage rate. ${ }^{55}$ Lastly, Grossman's model predicts that if education increases the efficiency with which gross investments in health are produced, then the more educated would demand a larger optimal stock of health. ${ }^{55}$ Grossman's model of demand for health enables one to study the effects of demographic variables like age and education without assuming that these variables are positively or negatively correlated with consumers' "tastes" for health. ${ }^{55}$

In our study, age refers to the age of women at the time of the household survey and was categorized as 15-24, 25-34, and 35+ years. Educational status refers to the highest level of education attained by women and was categorized into no education, primary education, secondary or higher education. The place of residence refers to the location of a woman's 
residence, grouped into urban and rural areas. Nigeria is divided into six geo-political zones: North Central, North East, North West, South East, South West and South South. A SES index was constructed using principal components analysis (PCA) based on data from variables on household ownership of assets and housing conditions. ${ }^{56}$ These variables include ownership of a car/truck, ownership of radio, ownership of refrigerator, ownership of bicycle, ownership of motorcycle, main wall material, main floor material, main roof material, type of fuel for cooking, source of electricity, source of drinking water, time to get to water source and type of toilet facility used. PCA generated factor score on each household asset. The resulting asset scores were standardised while the standardised scores were used to generate SES quintile as poorest, poorer, middle, richer and richest. Marital status describes the type of marital relationship a woman was in and was categorised as never married, married, living with partner, widowed, divorced and separated. Religion refers to the religious affiliation of women and was recoded as Christian, Muslim and Traditionalist/others. Employment status describes the type of employment women were engaged in and was recoded as not working, formal and informal worker. Household size was defined according to the survey questionnaire and recoded as less than five members and five or more members. Gender of household head was defined according to the survey questionnaire and recorded as male and female. Table 1 presents a summary of the study variables.

\section{Statistical Analysis}

Data were analysed using STATA version 12 software. Descriptive statistics was used to analyse the household and individual characteristics of the study sample as well as the outcome variable in the form of frequency tables and simple percentages. Pearson's chi-square analysis was used to test for associations between independent variables and health insurance status. Thereafter, multivariate logistic regression was used to examine associations between the dependent variable (health insurance coverage) and the independent

Table 1. Summary of the Study Variables

\begin{tabular}{|c|c|c|}
\hline Variables & Definition of Variables & Variables Description/Coding \\
\hline Health insurance coverage & Coverage by any form of health insurance & Dummy: 1 = Yes, 0 = No \\
\hline Age & Age of women at the time of the household survey & $\begin{array}{l}\text { Ordered categorical variable with three outcomes } \\
0-15-24 \text { years } \\
1-25-34 \text { years } \\
2-35 \text { years or older }\end{array}$ \\
\hline Educational status & The highest level of education attained by women & $\begin{array}{l}\text { Ordered categorical variable with three outcomes } \\
0 \text { - No education } \\
\text { 1- Primary education } \\
\text { 2- Secondary or higher education }\end{array}$ \\
\hline Place of residence & Location of a woman's residence & Dummy: Rural = 1, Urban = 0 \\
\hline Geo-political zone & Region where respondents reside & $\begin{array}{l}\text { Categorical variable with six outcomes } \\
\text { 1- North Central } \\
\text { 2- North East } \\
\text { 3- North West } \\
\text { 4- Soouth East } \\
\text { 5- South South } \\
\text { 6- South West }\end{array}$ \\
\hline Socio-economic status & Socio-economic position of women & $\begin{array}{l}\text { Ordered categorical variable with five outcomes } \\
\text { 1- Poorest } \\
\text { 2- Second poorest } \\
\text { 3- Middle } \\
\text { 4- Second richest } \\
\text { 5- Richest }\end{array}$ \\
\hline Marital status & The type of marital relationship a woman was in & $\begin{array}{l}\text { Ordered categorical variable with six outcomes } \\
\text { 0- Never married } \\
\text { 1- Married } \\
\text { 2- Living with partner } \\
\text { 3- Widowed } \\
\text { 4- Divorced } \\
\text { 5- Separated }\end{array}$ \\
\hline Religion & Religious affiliation of women & $\begin{array}{l}\text { Ordered categorical variable with three outcomes } \\
\text { 0- Christian } \\
\text { 1- Muslim } \\
\text { 2- Traditionalist/others }\end{array}$ \\
\hline Employment status & The type of employment women were engaged in & $\begin{array}{l}\text { Ordered categorical variable with three outcomes } \\
\text { 0- Not working } \\
\text { 1- Formal worker } \\
\text { 2- Informal worker }\end{array}$ \\
\hline Household size & The number of household members & $\begin{array}{l}0 \text { - Less than five members } \\
1 \text { - Five or more members }\end{array}$ \\
\hline Gender of household head & Gender of household head & Dummy: 1 = Female, 0 = Male \\
\hline
\end{tabular}


variables (age, educational status, place of residence, geopolitical zone, SES, marital status, religion, employment status, household size and gender of household head). Binary logistic regression was run since the dependent variable (health insurance coverage) has binary outcomes (Yes or No). Using the equation in the binary logistic regression model:

$\mathrm{y}=\beta_{o}+\beta_{i} X_{i}+\beta_{2} X_{2}+\beta_{3} X_{3} \cdots . . \beta_{n} X_{n}+E_{i}$

Where $y$ is the outcome/dependent variables, $\beta_{o}$ is the constant/ intercept, $\beta_{i} \ldots \beta_{n}$ are the regression coefficients and the $X_{i} \ldots$ $X_{n}$ are a collection of independent/explanatory variables and $E_{i}$ is the error term. Tests were done at a confidence level of $95 \%$ and at $5 \%$ significance level.

\section{Results}

\section{Descriptive Statistics}

Figure shows health insurance coverage for women of reproductive age in Nigeria. Only $2.1 \%$ of women had health insurance coverage. A total of $97.9 \%$ did not have health insurance coverage.

\section{Predictors of NHIS Enrolment Among Women of Reproductive Age}

Table 2 presents the study population characteristics and bivariate analysis of the predictors of NHIS enrolment among women of reproductive age.

Results from the bivariate analysis of the association between health insurance coverage and explanatory variables showed that the percentage of the insured was significantly higher among women aged 35 years or older (2.63\%). The proportion of the insured was significantly higher among women with secondary or higher education (4.04\%). The percentage of the insured was significantly higher among women residing in urban areas (3.86\%). The proportion of the insured was significantly higher among women from North Central region $(4.00 \%)$ and South South region (3.00\%). The percentage of the insured was higher among women from richest households (6.89\%). The proportion of the insured was significantly higher among women who are formal worker (13.14\%). The percentage of the insured was significantly higher among women who are Christians (2.99\%). The proportion of the insured was significantly higher among women with less than five members in their household (2.51\%). The percentage of the insured was significantly higher among women from households with female heads $(2.69 \%)$. Only variables that were statistically significant in the bivariate analysis were included in the logistic regression model.

Table 3 presents results of the predictors of enrolment in the NHIS among women of reproductive age using logistic regression model.

Results showed that the odds of having health insurance coverage was significantly higher for women aged 25-34 years (odds ratio [OR]: 1.71; 95\% CI: 1.39-2.09) and 35 years or older (OR: 2.23; 95\% CI: 1.79-2.78) compared with women who are aged 15-24 years. Women with secondary or higher education were 3.07 times more likely to have health insurance coverage compared to women with primary education and no

\section{$\%$ of women with health insurance coverage}

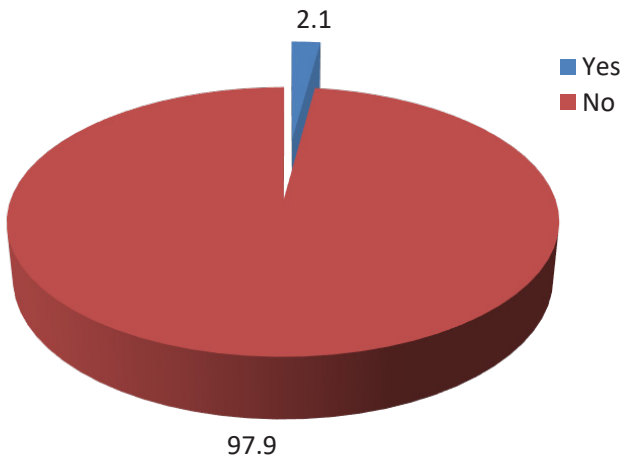

Figure. Health Insurance Coverage for Women of Reproductive Age in Nigeria.

education. The odds of having health insurance coverage was significantly lower among women from North West region (OR: 0.52; 95\% CI: 0.38-0.70), South East region (OR: 0.36; 95\% CI: 0.28-0.47), South South region (OR: 0.57; 95\% CI: $0.46-0.70$ ) and South West region (OR: 0.27; 95\% CI: $0.21-$ 0.34 ). Women from middle income, richer and richest households were $10.77,21.43$ and 57.67 times more likely to have health insurance coverage compared with women from poorer and poorest households. The odds of having health insurance coverage was significantly higher among women employed in the formal sector (OR: 2.82; 95\% CI: 2.27-3.50) compared with women not working and women working in the informal sector.

\section{Discussion}

This study examined the predictors of enrolment in the NHIS among women of reproductive age in Nigeria. We found that a high proportion of women (97.9\%) had no health insurance coverage. This could be due to large proportion of the Nigerian population in the informal sector, high level of poverty and voluntary contributory health insurance scheme targeted at the poor and informal sector workers. However, the low level of enrolment in the NHIS is consistent with other studies in Africa. ${ }^{3,30,31,35}$ Our study also revealed that women aged 25-34 years and 35 years or older were more likely to have health insurance coverage. This suggests that older women have financial security because they are usually employed whether in the formal or informal sector compared with younger ones. Also, older women have high risk of illness due to increase in age and this may lead to their increased investments in health including the purchase of health insurance in order to protect themselves from financial uncertainties and the risk of illness..$^{22,27,31,35,57}$ However, the finding corroborates results from similar studies. ${ }^{3,22,25,26,27,31,35}$ Results showed that women with secondary or higher education were more likely to have health insurance coverage compared with women with no education. A possible reason is that women who are educated have more knowledge about the advantages of health insurance and make informed choices about their health including purchasing health insurance. This finding is supported by results from other studies. ${ }^{3,22,23,26,31,33,35,36,39,40}$ We also found that place of residence was not a significant predictor of enrolment 
Table 2. Study Population Characteristics and Bivariate Analysis of the Predictors of NHIS Enrolment Among Women of Reproductive Age

\begin{tabular}{|c|c|c|c|c|}
\hline \multirow{3}{*}{$\begin{array}{l}\text { Demographic and Socio-economic } \\
\text { Characteristics }\end{array}$} & \multicolumn{3}{|c|}{ Health Insurance Coverage } & \multirow{3}{*}{$P$ Value } \\
\hline & Total $(\mathrm{N}=38948)$ & No $(n=38128)$ & Yes $(n=820)$ & \\
\hline & No. $\%$ & No. \% & No. $\%$ & \\
\hline Age & & & & $<.001^{* *}$ \\
\hline $15-24$ & $14619(37.50)$ & $14423(98.66)$ & $196(1.34)$ & \\
\hline $25-34$ & 12410 (31.90) & 12099 (97.49) & $311(2.51)$ & \\
\hline $35+$ & $11919(30.60)$ & 11606 (97.37) & $313(2.63)$ & \\
\hline Educational status & & & & $<.001 * *$ \\
\hline No education & $13740(35.30)$ & 13704 (99.74) & $36(0.26)$ & \\
\hline Primary education & $7104(18.20)$ & 7051 (99.25) & $53(0.75)$ & \\
\hline Secondary or higher education & $18104(46.50)$ & $17373(95.96)$ & $731(4.04)$ & \\
\hline Place of residence & & & & $<.001^{* *}$ \\
\hline Urban & $15545(39.90)$ & $14945(96.14)$ & $600(3.86)$ & \\
\hline Rural & $23403(60.10)$ & 23183 (99.06) & $220(0.94)$ & \\
\hline Geo-political zones & & & & $<.001^{* *}$ \\
\hline North Central & $6251(16.00)$ & $6001(96.00)$ & $250(4.00)$ & \\
\hline North East & $6630(17.00)$ & $6523(98.39)$ & $107(1.61)$ & \\
\hline North West & $9673(24.80)$ & 9613 (99.38) & $60(0.62)$ & \\
\hline South East & $4462(11.50)$ & 4372 (97.98) & $90(2.02)$ & \\
\hline South South & $6058(15.60)$ & $5876(97.00)$ & $182(3.00)$ & \\
\hline South West & $5874(15.10)$ & 5743 (97.77) & $131(2.23)$ & \\
\hline Socio-economic status & & & & $<.001^{* *}$ \\
\hline Poorest & $6602(17.00)$ & 6599 (99.95) & $3(0.05)$ & \\
\hline Poorer & 7515 (19.30) & 7504 (99.85) & $11(0.15)$ & \\
\hline Middle & 8001 (20.50) & 7937 (99.20) & $64(0.80)$ & \\
\hline Richer & 8450 (21.70) & 8285 (98.05) & 165 (1.95) & \\
\hline Richest & $8380(21.50)$ & 7803 (93.11) & 577 (6.89) & \\
\hline Employment status & & & & $<.001^{* *}$ \\
\hline Not working & $14262(36.60)$ & $14034(98.40)$ & $228(1.60)$ & \\
\hline Formal worker & $2162(5.60)$ & $1878(86.86)$ & $284(13.14)$ & \\
\hline Informal worker & $22524(57.80)$ & $22216(98.63)$ & $308(1.37)$ & \\
\hline Religion & & & & $<.001^{* *}$ \\
\hline Christian & $19838(50.90)$ & 19245 (97.01) & $593(2.99)$ & \\
\hline Muslim & $18578(47.70)$ & 18353 (98.79) & $225(1.21)$ & \\
\hline Traditionalists/others & $532(1.40)$ & $530(99.62)$ & $2(0.38)$ & \\
\hline Marital status & & & & .537 \\
\hline Not married & $9820(25.20)$ & 9617 (97.93) & $203(2.07)$ & \\
\hline Married & $26403(67.80)$ & 25836 (97.85) & $567(2.15)$ & \\
\hline Living with partner & $871(2.20)$ & 853 (97.93) & $18(2.07)$ & \\
\hline Widowed & $993(2.50)$ & 971 (97.78) & $22(2.22)$ & \\
\hline Divorced & $432(1.10)$ & $427(98.84)$ & $5(1.16)$ & \\
\hline Separated & $429(1.10)$ & $424(98.83)$ & $5(1.17)$ & \\
\hline Household size & & & & $<.001 * *$ \\
\hline Less than five members & $12829(32.90)$ & 12507 (97.49) & $322(2.51)$ & \\
\hline Five or more members & $26119(67.10)$ & 25621 (98.09) & $498(1.91)$ & \\
\hline Gender of household head & & & & $<.001 * *$ \\
\hline Male & $31838(81.70)$ & 31209 (98.02) & 629 (1.98) & \\
\hline Female & $7110(18.30)$ & $6919(97.31)$ & $191(2.69)$ & \\
\hline
\end{tabular}

Abbreviation: NHIS, National Health Insurance Scheme; SES, Socio-economic status.

$* * P<0.05$.

in the NHIS among women. A possible explanation is that women from poor households who are unable to pay insurance contributions live in both rural and urban areas. Also, women who work in the informal sector are also spread across rural and urban areas. However, this finding is in contrast to results from other studies. ${ }^{22,26,27,34,35,38}$ In this study, women in North West region, South East region, South South region and South West region were less likely to have health insurance. The low level of enrolment in these geographical locations could be due to the fact that they are predominantly rural and have a high proportion of women from poor households who do not have knowledge of the advantages of health insurance. Furthermore, most of the health insurance organizations are concentrated in urban areas and not within the reach of women residing in rural areas. This finding is consistent with similar studies that found that geopolitical zone was associated with lower odds of having health insurance coverage. ${ }^{31,35}$ Also, women from middle income, richer and richest households were more likely to have health insurance coverage compared with women from poorest 
Table 3. Predictors of NHIS Enrolment Among Women of Reproductive Age Using Logistic Regression Model

\begin{tabular}{|c|c|c|}
\hline \multirow{2}{*}{$\begin{array}{l}\text { Demographic and Socio-Economic } \\
\text { Characteristics }\end{array}$} & \multicolumn{2}{|c|}{ Health Insurance Coverage } \\
\hline & OR & $95 \% \mathrm{Cl}$ \\
\hline \multicolumn{3}{|l|}{ Age } \\
\hline $15-24$ & 1 & 1 \\
\hline $25-34$ & $1.71^{* *}$ & $(1.39-2.09)$ \\
\hline $35+$ & $2.23 * *$ & $(1.79-2.78)$ \\
\hline \multicolumn{3}{|l|}{ Educational status } \\
\hline No education & 1 & 1 \\
\hline Primary education & 1.24 & $(0.79-1.93)$ \\
\hline Secondary or higher education & $3.07 * *$ & $(2.08-4.52)$ \\
\hline \multicolumn{3}{|l|}{ Place of residence } \\
\hline Urban & 1 & 1 \\
\hline Rural & 0.86 & $(0.72-1.04)$ \\
\hline \multicolumn{3}{|l|}{ Geo-political zone } \\
\hline North Central & 1 & 1 \\
\hline North East & 1.04 & $(0.81-1.34)$ \\
\hline North West & $0.52 * *$ & $(0.38-0.70)$ \\
\hline South East & $0.36 * *$ & $(0.28-0.47)$ \\
\hline South South & $0.57^{* *}$ & $(0.46-0.70)$ \\
\hline South West & $0.27 * *$ & $(0.21-0.34)$ \\
\hline \multicolumn{3}{|l|}{ SES } \\
\hline Poorest & 1 & 1 \\
\hline Poorer & 2.62 & $(0.73-9.47)$ \\
\hline Middle & $10.77 * *$ & $(3.30-35.13)$ \\
\hline Richer & $21.43^{* *}$ & $(6.60-69.64)$ \\
\hline Richest & $57.67 * *$ & $(17.66-188.30)$ \\
\hline \multicolumn{3}{|l|}{ Employment status } \\
\hline Not working & 1 & 1 \\
\hline Formal worker & $2.82^{* *}$ & $(2.27-3.50)$ \\
\hline Informal worker & 0.83 & $(0.68-1.01)$ \\
\hline \multicolumn{3}{|l|}{ Religion } \\
\hline Christian & 1 & 1 \\
\hline Muslim & 0.90 & $(0.74-1.10)$ \\
\hline Traditionalists/others & 0.34 & $(0.08-1.40)$ \\
\hline \multicolumn{3}{|l|}{ Household size } \\
\hline Less than five members & 1 & 1 \\
\hline Five or more members & 1.09 & $(0.93-1.27)$ \\
\hline \multicolumn{3}{|l|}{ Gender of household head } \\
\hline Male & 1 & 1 \\
\hline Female & 1.02 & $(0.85-1.22)$ \\
\hline
\end{tabular}

Abbreviations: OR, odds ratio; NHIS, National Health Insurance Scheme; SES, Socio-economic status.

$* * P<0.05$

households. A possible explanation is that women in poorest households have limited access to resources and cannot afford health insurance plans and experience difficulty in paying premium contributions. The finding is consistent with other studies that showed that higher SES is an important predictor of enrolment in NHIS. $3,22,23,26,31,33,34,37,38,41,42$ Being a formal worker was a significant predictor of enrolment in NHIS among women of reproductive age in this study. A plausible explanation for this observation is that formal workers earn income that is easily deducted as part of contribution towards the purchase of health insurance. Also, this could be due to the fact that the unemployed and workers in the informal sector are not economically empowered to pay premium contributions. This finding is consistent with similar studies in Africa. ${ }^{3,22,24,31,33,35,40}$ The wide gap between health insurance coverage for formal and informal workers have implications on the use of voluntary contributory health insurance schemes to expand health insurance coverage to informal sector workers. Both the VHI and CBHI schemes have provided limited coverage to the poor and informal sector workers. Evidence suggests that it is difficult for contributory insurance schemes to achieve UHC given a large informal sector population. ${ }^{58-60}$ This means that the current health financing mechanism cannot assist the country in moving towards UHC. Results from this study also showed that religious affiliation was not a significant predictor of enrolment in the NHIS among women. A possible explanation is that enrolment in the NHIS is not opposed by religious institutions due to the advantages of health insurance. This is in line with findings from a similar study in Ghana. ${ }^{34}$ In this study, household size was not a significant predictor of enrolment in the NHIS among women in Nigeria. This suggests that all members of a household regardless of their size should be covered by health insurance. However, the finding is in contrast to similar studies. ${ }^{3,22,26,27}$ Gender of household head was not a significant predictor of the NHIS enrolment among women. A plausible explanation is that both male and female headed households face the risk of ill-health and should be concerned about protecting their household. A study in rural Burkina Faso supports this finding ${ }^{23}$ but the result is in contrast to similar studies in Africa that found that women residing in female-headed households were more likely to have health insurance coverage compared with women from male-headed households. ${ }^{27,31}$

Findings from this study have implications for policy-makers in Nigeria. First, some factors predict enrolment in the NHIS among women of reproductive age. Policy-makers need to target these factors in their effort to increase the level of enrolment in the NHIS among women. Second, women from poor households and those working in the informal sector are excluded from the NHIS. This implies that the NHIS is not a pro-poor health financing policy. Therefore, there is a need to adopt a tax-financed non-contributory health insurance scheme as the primary financing mechanism in order to expand health insurance coverage to women from poor households and those working in the informal sector. The provision of health insurance to poor women and those working in the informal sector represents a bottom-up approach to expanding health insurances coverage which is a viable option for developing countries including Nigeria. ${ }^{61}$

\section{Limitations of the study}

Our study has some limitations that nevertheless do not invalidate our work. First, the study used cross-sectional secondary data; hence, causality for the factors associated with enrolment in the NHIS could not be established. Second, findings from our study are affected by recall bias due to self-reported information. Third, the study did not include important variables such as health status, type of facility visited and type of illness suffered due to their unavailability in the NDHS dataset. Finally, data from the 2013 NDHS may be old in informing policy decisions but it is the most recent NDHS dataset available to the public after the release of the 


\section{NDHS data.}

\section{Conclusion}

This study concludes that health insurance coverage among women of reproductive age in Nigeria is very low. Additionally, socio-demographic factors such as age, education, geopolitical zone, SES and employment status were significant predictors of enrolment in NHIS among women of reproductive age. This implies that the NHIS is not a pro-poor health financing policy as a high proportion of women from the poorest and poorer households lack health insurance coverage. Furthermore, effort to expand health insurance coverage to women from poor households and those working in the informal sector through voluntary contributory health insurance schemes may not be feasible due to financial constraint and difficulty in collecting contributions among these groups. Therefore, governments and policy-makers should establish a tax-based health financing mechanism specifically targeted at women who are young, uneducated, from poorest households, unemployed and working in the informal sector. Extending health insurance coverage to women from poor households and those who work in the informal sector through a tax-financed non-contributory health insurance scheme would accelerate progress towards UHC.

\section{Ethical issues}

In obtaining the micro data, a request was made on the DHS program website on March 6, 2018 and approval was granted to download the data on the same day, hence, there were no ethical issues of concern. Issues of informed consent, confidentiality, anonymity and privacy of the study sample were addressed by the Institutional Review Board (IRB) of ICF Macro International in the United States and National Health Research Ethics Committee (NHREC) of the Federal Ministry of Health (FMoH).

\section{Competing interests}

Authors declare that they have no competing interests.

\section{Authors' contributions}

BSA: Conception and design; acquisition of data; analysis and interpretation of data; and drafting of the manuscript. SMK: Analysis and interpretation of data; and drafting of the manuscript. Both authors reviewed the manuscript for important intellectual content and approved the final draft for publication.

\section{Authors' affiliations}

${ }^{1}$ Department of Community Health \& Primary Care, College of Medicine, University of Lagos, Lagos, Nigeria. ${ }^{2}$ Department of Public Health Sciences, Karolinska Institutet, Stockholm, Sweden.

\section{References}

1. International Labour Office. Women and men in the informal economy: A statistical picture. 3rd ed. Geneva: International Labour Office; 2018.

2. Wolfe R. Expanding health coverage for those outside the formal sector. 2013. http://resyst.Ishtm.ac.uk/sites/resyst.Ishtm.ac.uk/files/ docs/reseources/Financial\%20protection\%20brief.pdf. Accessed February 8, 2018.

3. Kazungu JS, Barasa EW. Examining levels, distribution and correlates of health insurance coverage in Kenya. Trop Med Int Health. 2017;22(9):1175-1185. doi:10.1111/tmi.12912

4. Smith KV, Sulzbach S. Community-based health insurance and access to maternal health services: evidence from three West African countries. Soc Sci Med. 2008;66(12):2460-2473. doi:10.1016/j.socscimed.2008.01.044

5. Wang $\mathrm{H}$, Yip W, Zhang L, Hsiao WC. The impact of rural mutual health care on health status: evaluation of a social experiment in rural China. Health Econ. 2009;18 Suppl 2:S65-82. doi:10.1002/ hec. 1465

6. Kozhimannil KB, Valera MR, Adams AS, Ross-Degnan D. The population-level impacts of a national health insurance program and franchise midwife clinics on achievement of prenatal and delivery care standards in the Philippines. Health Policy. 2009;92(1):55-64. doi:10.1016/j.healthpol.2009.02.009

7. Mensah J, Oppong JR, Schmidt CM. Ghana's National Health Insurance Scheme in the context of the health MDGs: an empirical evaluation using propensity score matching. Health Econ. 2010;19 Suppl:95-106. doi:10.1002/hec.1633

8. Escobar ML, Griffin CC, Shaw RP. The impact of health insurance in low- and middle-income countries. Washington, DC: Brookings Institution Press; 2010.

9. Hong R, Ayad M, Ngabo F. Being insured improves safe delivery practices in Rwanda. J Community Health. 2011;36(5):779-784. doi:10.1007/s10900-011-9376-4

10. Dong H, Escobar ML, Griffin CC, Shaw RP. The impact of health insurance in low-and-middle-income countries. Journal of International Development. 2012;24:529-530.

11. Nguyen HT, Hatt $L$, Islam $M$, et al. Encouraging maternal health service utilization: an evaluation of the Bangladesh voucher program. Soc Sci Med. 2012;74(7):989-996. doi:10.1016/j. socscimed.2011.11.030

12. Witter S, Garshong B. Something old or something new? Social health insurance in Ghana. BMC Int Health Hum Rights. 2009;9:20. doi:10.1186/1472-698x-9-20

13. World Health Organization. Sustainable health financing, universal coverage and social health insurance. Geneva: World Health Organization; 2005.

14. United Nations. Transforming our world: The 2030 agenda for sustainable development. 2015. https://sustainabledevelopment. un.org/post2015/transformingourworld/publication. Accessed February 8, 2018.

15. Aregbeshola BS. Enhancing Political Will for Universal Health Coverage in Nigeria. MEDICC Rev. 2017;19(1):42-46. doi:10.1590/ medicc.2017.190100010

16. World Health Organization, World Bank. Tracking universal health coverage: 2017 Global Monitoring Report. Switzerland: World Health Organization and World Bank; 2017.

17. World Health Organization. World Health Statistics 2018: Monitoring health for the SDGs. Geneva: World Health Organization; 2018.

18. Onoka CA, Onwujekwe OE, Uzochukwu BS, Ezumah NN. Promoting universal financial protection: constraints and enabling factors in scaling-up coverage with social health insurance in Nigeria. Health Res Policy Syst. 2013;11:20. doi:10.1186/1478-4505-11-20

19. Okebukola PO, Brieger WR. Providing Universal Health Insurance Coverage in Nigeria. Int Q Community Health Educ. 2016;36(4):241246. doi:10.1177/0272684x16657451

20. Mclntyre D, Ranson MK, Aulakh BK, Honda A. Promoting universal financial protection: evidence from seven low- and middle-income countries on factors facilitating or hindering progress. Health Res Policy Syst. 2013;11:36. doi:10.1186/1478-4505-11-36

21. Jutting JP. Do Community-based health insurance schemes improve poor people's access to health care? Evidence from rural Senegal. World Dev. 2004;32(2):273-288. doi:10.1016/j. worlddev.2003.10.001

22. Kirigia JM, Sambo LG, Nganda B, Mwabu GM, Chatora R, Mwase T. Determinants of health insurance ownership among South African women. BMC Health Serv Res. 2005;5(1):17. doi:10.1186/14726963-5-17

23. De Allegri $\mathrm{M}$, Kouyate $\mathrm{B}$, Becher $\mathrm{H}$, et al. Understanding enrolment in community health insurance in sub-Saharan Africa: a populationbased case-control study in rural Burkina Faso. Bull World Health Organ. 2006;84(11):852-858.

24. Mathauer I, Schmidt JO, Wenyaa M. Extending social health insurance to the informal sector in Kenya. An assessment of factors affecting demand. Int $\mathrm{J}$ Health Plann Manage. 2008;23(1):51-68. doi:10.1002/hpm.914

25. Onwujekwe O, Okereke E, Onoka C, Uzochukwu B, Kirigia J, Petu A. Willingness to pay for community-based health insurance in Nigeria: do economic status and place of residence matter? Health 
Policy Plan. 2010;25(2):155-161. doi:10.1093/heapol/czp046

26. Kiplagat I, Muriithi M, Kioko U. Determinants of health insurance choice in Kenya. Eur Sci J. 2013;9(13):452-468.

27. Jehu-Appiah C, Aryeetey G, Spaan E, de Hoop T, Agyepong I, Baltussen R. Equity aspects of the National Health Insurance Scheme in Ghana: Who is enrolling, who is not and why? Soc Sci Med. 2011;72(2):157-165. doi:10.1016/j.socscimed.2010.10.025

28. Dixon J, Tenkorang EY, Luginaah I. Ghana's National Health Insurance Scheme: helping the poor or leaving them behind? Environ Plann C Gov Policy. 2011;29(6):1102-1115. doi:10.1068/ c1119r

29. Dixon J, Luginaah I, Mkandawire P. The National Health Insurance Scheme in Ghana's Upper West Region: a gendered perspective of insurance acquisition in a resource-poor setting. Soc Sci Med. 2014;122:103-112. doi:10.1016/j.socscimed.2014.10.028

30. Kimani JK, Ettarh R, Kyobutungi C, Mberu B, Muindi K. Determinants for participation in a public health insurance program among residents of urban slums in Nairobi, Kenya: results from a cross-sectional survey. BMC Health Serv Res. 2012;12:66. doi:10.1186/1472-6963-12-66

31. Kimani JK, Ettarh R, Warren C, Bellows B. Determinants of health insurance ownership among women in Kenya: evidence from the 2008-09 Kenya demographic and health survey. Int J Equity Health. 2014;13:27. doi:10.1186/1475-9276-13-27

32. Akazili J, Welaga P, Bawah A, et al. Is Ghana's pro-poor health insurance scheme really for the poor? Evidence from Northern Ghana. BMC Health Serv Res. 2014;14:637. doi:10.1186/s12913014-0637-7

33. Bonfrer I, Breebaart L, Van de Poel E. The Effects of Ghana's National Health Insurance Scheme on Maternal and Infant Health Care Utilization. PLoS One. 2016;11(11):e0165623. doi:10.1371/ journal.pone.0165623

34. Kusi A, Fenny AP, Arhinful DK, Asante FA, Parmar D. Determinants of enrollment in the NHIS for women in Ghana. Int $J$ Soc Econ. 2017. doi:10.1108/IJSE-10-2016-0291

35. Mulenga JN, Bwalya BB, Gebremeskel Y. Demographic and Socioeconomic determinants of maternal health insurance coverage in Zambia. Epidemiol Biostat Public Health. 2017;14(1):e12094-1e12094-9. doi:10.2427/12094

36. Boateng D, Awunyor-Vitor D. Health insurance in Ghana: evaluation of policy holders' perceptions and factors influencing policy renewal in the Volta region. Int J Equity Health. 2013;12:50. doi:10.1186/1475-9276-12-50

37. Kumi-Kyereme A, Amo-Adjei J. Effects of spatial location and household wealth on health insurance subscription among women in Ghana. BMC Health Serv Res. 2013;13:221. doi:10.1186/14726963-13-221

38. Sarpong N, Loag W, Fobil J, et al. National health insurance coverage and socio-economic status in a rural district of Ghana. Trop Med Int Health. 2010;15(2):191-197. doi:10.1111/j.13653156.2009.02439.x

39. Wang W, Temsah G, Mallick L. Health insurance coverage and its impact on maternal health care utilization in low- and middle-income countries. DHS Analytical Studies No. 45. Rockville, Maryland, USA: ICF International; 2014.

40. Chankova S, Sulzbach S, Diop F. Impact of mutual health organizations: evidence from West Africa. Health Policy Plan. 2008;23(4):264-276. doi:10.1093/heapol/czn011

41. Basaza R, Criel B, Van der Stuyft P. Community health insurance in Uganda: why does enrolment remain low? A view from beneath. Health Policy. 2008;87(2):172-184. doi:10.1016/j. healthpol.2007.12.008

42. Dong H, Gbangou A, De Allegri M, Pokhrel S, Sauerborn R. The differences in characteristics between health-care users and nonusers: implication for introducing community-based health insurance in Burkina Faso. Eur J Health Econ. 2008;9(1):41-50. doi:10.1007/ s10198-006-0031-4

43. National Health Insurance Scheme. National health insurance scheme decree No 35 of 1999. http://www.nigeria-law.org/ National\%20Health\%20Insurance\%20Scheme\%20Decree.htm. Accessed February 8, 2018.

44. Giedion U, Alfonso EA, Diaz Y. The impact of universal coverage schemes in the developing world: a review of the existing evidence. Washington, DC: World Bank; 2013. UNICO Studies Series 25.

45. World Health Organization. Nigeria: Factsheets of health statistics 2016. http://www.aho.afro.who.int/profiles_information/images/3/3b/ Nigeria-Statistical_Factsheet.pdf. Accessed March 30, 2018.

46. Mclntyre D, Thiede M, Dahlgren G, Whitehead M. What are the economic consequences for households of illness and of paying for health care in low- and middle-income country contexts? Soc Sci Med. 2006;62(4):858-865. doi:10.1016/j.socscimed.2005.07.001

47. Aregbeshola BS, Khan SM. Out-of-Pocket Payments, Catastrophic Health Expenditure and Poverty Among Households in Nigeria 2010. Int J Health Policy Manag. 2018; forthcoming. doi:10.15171/ ijhpm.2018.19

48. Wagstaff A. Health insurance for the poor: initial impacts of Vietnam's health care fund for the poor. Policy Research Working Paper, 4134. World Bank; 2007.

49. Aggarwal A. Impact evaluation of India's 'Yeshasvini' communitybased health insurance programme. Health Econ. 2010;19 Suppl:5-35. doi:10.1002/hec.1605

50. Wagner AK, Graves AJ, Reiss SK, Lecates R, Zhang F, RossDegnan D. Access to care and medicines, burden of health care expenditures, and risk protection: results from the World Health Survey. Health Policy. 2011;100(2-3):151-158. doi:10.1016/j. healthpol.2010.08.004

51. Odeyemi IA. Community-based health insurance programmes and the National Health Insurance Scheme of Nigeria: challenges to uptake and integration. Int $J$ Equity Health. 2014;13:20. doi:10.1186/1475-9276-13-20

52. Onoka CA, Hanson K, Mills A. Growth of health maintenance organisations in Nigeria and the potential for a role in promoting universal coverage efforts. Soc Sci Med. 2016;162:11-20. doi:10.1016/j.socscimed.2016.06.018

53. National Population Commission (NPC) [Nigeria], ICF Macro. Nigeria Demographic and Health Survey 2013. Abuja, Nigeria: National Population Commission and ICF Macro; 2014.

54. Aday LA, Andersen R. A framework for the study of access to medical care. Health Serv Res. 1974;9(3):208-220.

55. Grossman M. On the Concept of Health Capital and the Demand for Health. J Polit Econ. 1972;80(2):223-255. doi:10.1086/259880

56. Vyas S, Kumaranayake L. Constructing socio-economic status indices: how to use principal components analysis. Health Policy Plan. 2006;21(6):459-468. doi:10.1093/heapol/czl029

57. Marquis MS, Holmer MR. Alternative Models of Choice Under Uncertainty and Demand for Health Insurance. Rev Econ Stat. 1996;78(3):421-427. doi:10.2307/2109789

58. Tangcharoensathien $V$, Patcharanarumol $W$, Ir $P$, et al. Healthfinancing reforms in southeast Asia: challenges in achieving universal coverage. Lancet. 2011;377(9768):863-873. doi:10.1016/ s0140-6736(10)61890-9

59. Tangcharoensathien V, Pitayarangsarit S, Patcharanarumol W, et al. Promoting universal financial protection: how the Thai universal coverage scheme was designed to ensure equity. Health Res Policy Syst. 2013;11:25. doi:10.1186/1478-4505-11-25

60. Okungu V, Chuma J, Mulupi S, Mclntyre D. Extending coverage to informal sector populations in Kenya: design preferences and implications for financing policy. BMC Health Serv Res. 2018;18(1):13. doi:10.1186/s12913-017-2805-z

61. Cotlear D, Nagpal S, Smith O, Tandon A, Cortez R. Going Universal: How 24 countries are implementing universal health coverage reforms from the bottom up. Washington, DC: World Bank; 2016. 